\title{
Life prediction and experimental validation of a 3D printed dental Titanium Ti64ELI implant
}

${ }^{*}$ Lebogang Lebea ${ }^{1,2}$, Harry M Ngwangwa ${ }^{2}$, Dawood Desai ${ }^{1}$ Fhuluphelo Nemavhola ${ }^{2}$

\footnotetext{
${ }^{1}$ Department of Mechanical and Mechatronic Engineering, Tshwane University of Technology

${ }^{2}$ Unisa Biomechanics Research Group, Department of Mechanical and Industrial Engineering, University of South Africa

* Correspondence: lebealc@unisa.ac.za
}

\begin{abstract}
Fatigue analysis plays a vital role in determining the structural integrity and life of a dental implant. With the use of such implants on the rise, there is a corresponding increase in the number of implant failures. As such, the aim of this research paper is to investigate the life of 3D-printed dental implants. The dental implants considered in this study were 3D printed according to the direct metal laser sintering (DMLS) method. Additionally, a finite element model was developed to study their performance, while fatigue life was predicted using Fe-Safe software®. The model was validated experimentally by performing fatigue tests. The life of the dental implants was analysed based on Normal strain and the Brown-Miller with Morrow mean correction factor algorithm. The model revealed that there was a strong correlation between the FEA and the experimental results. The clinical success of 3D-printed dental implant experimentally is 20.51 years and computationally under Normal strain is 19.89 years and Brown-Miller with Morrow mean correction factor is 26.82 years.
\end{abstract}

Keywords: Fatigue, oblique loading, axial loading, finite element analysis, 3D-printed dental implant

\section{Introduction}

Dental diseases have a considerable impact not only on people's self-esteem but also on their eating ability, nutrition and health [1]. Problems concerning various aspects related to dental implants always remain relevant and aesthetics is the main reason why people often choose implants instead of other methods [2]. Dental implants are used to retain and support both fixed and removable dental prostheses [3] and have been reported as the preferred treatment modality for completely and partially edentulous patients [4]. Recently, three-dimensional printing (3D printing) technology has found its way into orthodontic surgery [5], [6]. Additive manufacturing allows a variety of materials to be used in $3 \mathrm{D}$ printing production. This printing technology facilitates the printing of complex geometries and allows for the creation of porous structures [7], [8]. There are different techniques by which 3D printing can be undertaken, with direct metal laser sintering (DMLS) being the most advanced of the available techniques [9], [10].

In dentistry, three-dimensional finite-element (FE) analysis has become an increasingly useful tool for the prediction of the effects of stress on the implant and its surrounding bone. A number of studies have been carried out to investigate the fatigue life of dental implants [11]-[13]. A numerical study was carried out to investigate the stress distribution between bone and dental implant and it was found that the stress is 
higher in a two-piece diameter implant as compared to a one-piece diameter implant [14]. Experimentally fractured dental implants were validated using FEA analysis with the results showing that FEA-predicted lifetime was within the $95 \%$ confidence interval of lifetime estimated by experimental results. This suggests that FEA prediction is accurate for this implant system [15]. Fatigue testing of narrow and extremely narrow dental implants demonstrated that the von-Mises stress at the dental implant and abutment has high reliability (up to $97.5 \%$ ) at 50 and $100 \mathrm{~N}$, with decreased reliability observed for both groups at 150 and $180 \mathrm{~N}$ (ranging from 0 to $82.3 \%$ ) [16].

The life prediction model plays a critical role in minimising technical problems relating to both the prosthesis and the dental implant components, including screw loosening or screw fractures, abutment fractures and implant fixture fractures. The use of fatigue life prediction models is well documented [17], [18]. The Morrow concept is suitable for low stress cycle fatigue and it was, furthermore, predicted that lifetime at loading $\mathrm{F}=357 \mathrm{~N}$ is equal to 7390092 cycles.

Weibull evaluations can obtain satisfactory results, but are subject to a large evaluation error at the boundary loading [19]. Experimental and numerical studies have been conducted to determine the life of the dental implant. However, despite many attempts, the fatigue life is not well established under the Brown-Miller with Morrow mean correction factor algorithm. The aim of this study is to numerically investigate the life of 3D printed dental implants under Normal strain and Brown-Miller with Morrow mean correction factor algorithm. The objective of this study was to validate experimentally by performing fatigue tests using an MTS Acumen fatigue testing machine 3D-printed dental implants as specimens.

\section{Methodology}

This section outlines the methodology that was previously used [11], [20]. The first section describes the stress analysis of the 3D printed dental implant model where the oblique loading is applied to simulate a worst-case scenario. The stress analysis results are then exported to Fe-Safe software ${ }^{\circledR}$ to perform fatigue analysis. The finite element analysis model is then validated experimentally by performing fatigue tests [19], [21].

\subsection{Finite element modelling}

Dental implants were designed using Abaqus CAE software with Fe-Safe software employed to perform fatigue analysis. The 3D model had three components, i.e., the crown, dental implant and specimen holder (see Figure 1). They were then connected as one body as shown in Figure 1 (B \& C). The dental implant and crown were modelled in titanium to mimic the experimental model.

Figure 1: $[\mathrm{A}]$ Crown and one piece dental implant, [B] 3D model of specimen holder, dental implant and crown assembly, [C] Section view of the 3D model assembly 


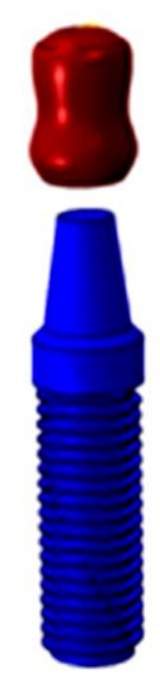

[A]

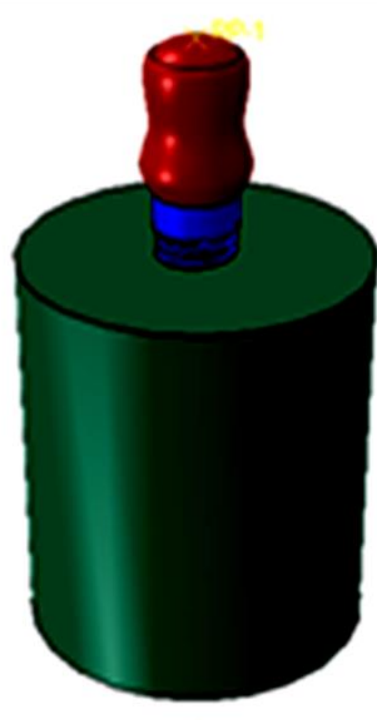

[B]

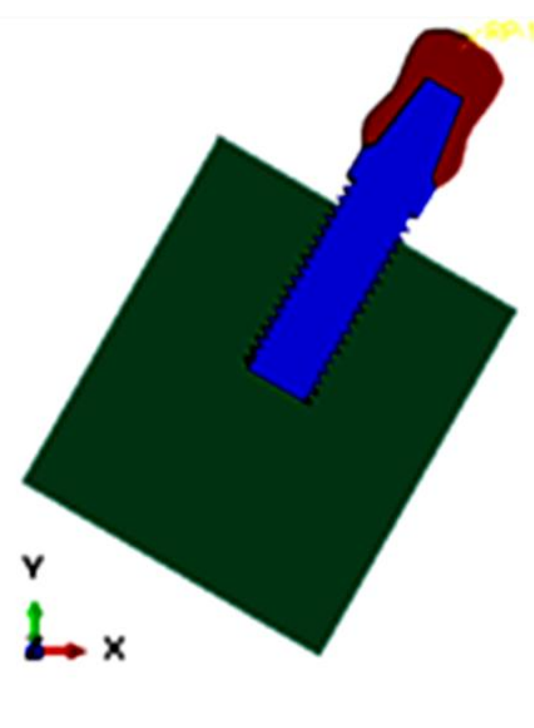

[C]

\subsubsection{Material properties}

All materials used in the model are considered to be isotropic, homogeneous, and linearly elastic. The elastic properties were taken from the literature, as seen in Table 1.

Table 1: Material properties utilised to perform finite elements analysis.

\begin{tabular}{lccc}
\hline & $\begin{array}{c}\text { E-Modulus } \\
{[\mathrm{MPa}]}\end{array}$ & $\begin{array}{c}\text { Poisson's } \\
\text { ratio [v] }\end{array}$ & Reference \\
\hline Crown & 114000 & 0,34 & {$[22]-[25]$} \\
Implant & 114000 & 0,34 & {$[22],[23],[26]$} \\
$\begin{array}{l}\text { Embedding } \\
\text { Material }\end{array}$ & 4400 & 0,29 & {$[19],[21]$} \\
\hline
\end{tabular}

\subsubsection{Finite element analysis mesh study}

Linear tetrahedron element (C3D4) was considered in the current study and this element type were previously used successfully [15], [23], [27]. The mesh convergence study was conducted and the results are presented in Figure 2. The total linear tetrahedron element (C3D4) was 223794. The mesh size were $1 \mathrm{~mm}$ around the specimen holder and $0.2 \mathrm{~mm}$ at the threaded interface. To minimize distortion, finer mesh were applied around the threads of dental implant and specimen holder. The mesh size was achieved by gradually reducing the default mesh size of the implant until the stress curve started to flatten out and a constant result was obtained.

Figure 2: [A] Mesh study graph, [B] Mesh size applied around the crown, implantspecimen holder interface and dental implant, $[\mathrm{C}]$ Detailed element size around the dental implant, crow and specimen holder 


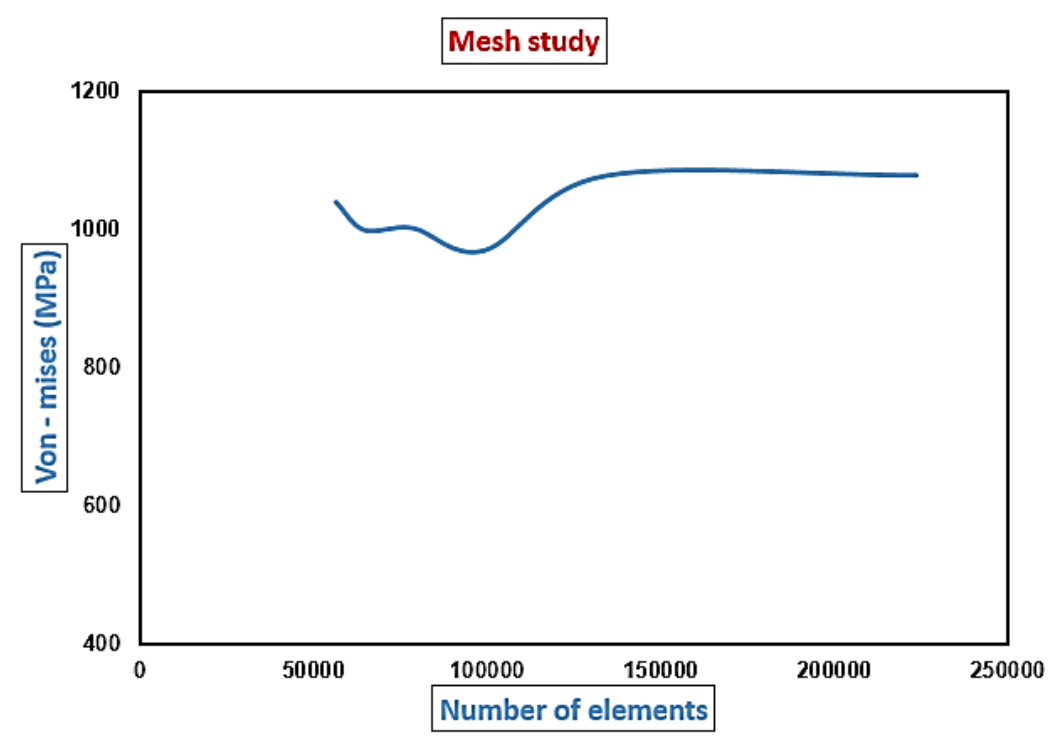

$[\mathrm{A}]$

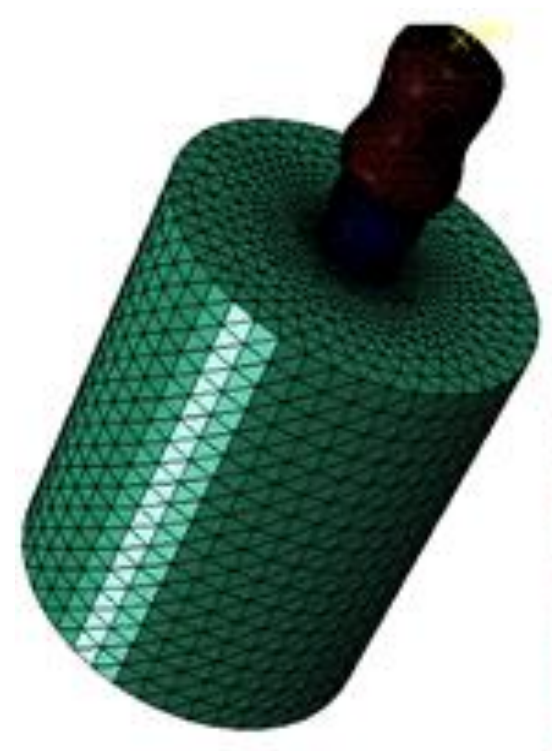

$[\mathrm{B}]$

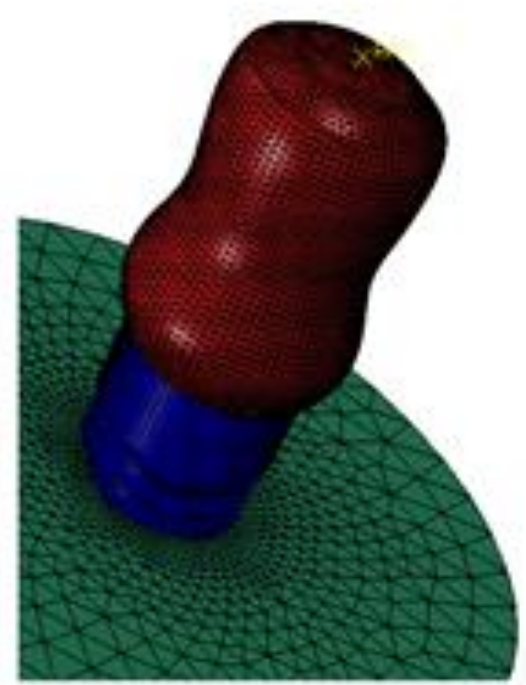

[C]

\subsubsection{Interface conditions and constraints}

The specimen holder-3D printed dental implant interface was assumed to be perfect simulating complete osseointegration [25], [28]. Therefore, connections between 3D printed dental implant, specimen holder and crown were designed to be bonded. Surface to surface constraints were applied between 3D printed dental implant, specimen holder and crown. The bottom of the specimen holder was fixed and thus other faces were free of the condition (see Figure 3). While chewing forces are dynamic, to simplify the problem, a static analysis is done in the majority of studies [29]. The specimen holder, crown and dental implant are inclined at $30^{\circ}$ to the horizontal while the force is applied vertically downwards at the centre of the crown. 
Figure 3: Boundary condition of the 3D model utilised to perform fine element analysis. The model was inclined at $30^{\circ}$ to the horizontal surface while the force is applied at vertical direction.

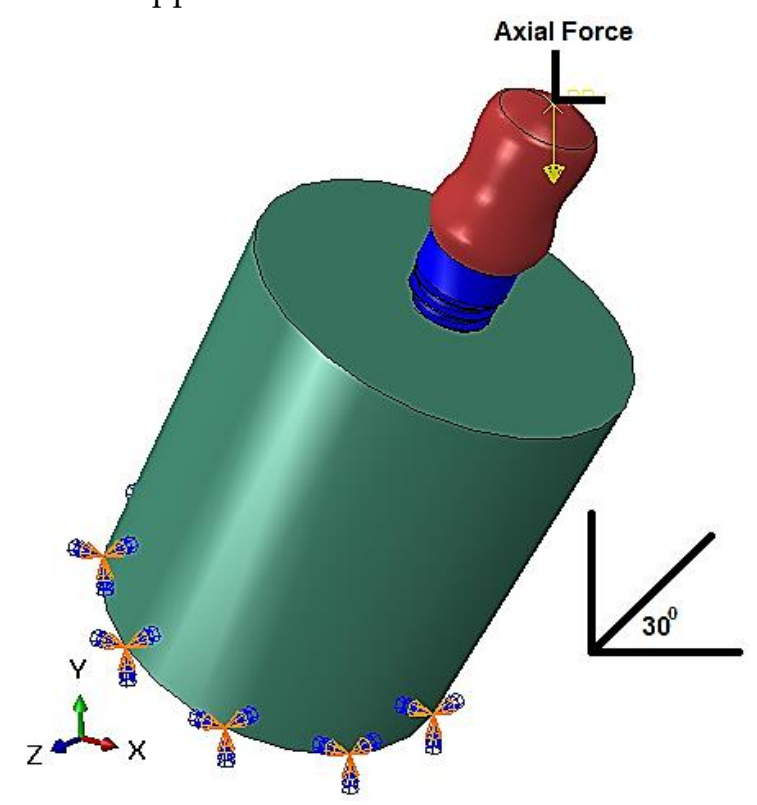

\subsection{Fatigue life model}

The fatigue life prediction models are developed subsequent to the FEA model and are based mainly on the cumulative damage to the materials under cyclic loadings. The models are formulated according to the correlation between the cyclic numbers and the local stresses and strains. A number of models have been developed in the literature [17], [30], [31]. In this project, Normal strain life and the Brown Miller with Morrow mean correction method are used - a method first discovered by Wohler - consisting of a plot of alternating stress (S) and cycle to failure (N) [15]. The strain-life method is based on the observation that, in many components, the response of the material in critical locations is strain dependent.

Equations 1-3, below, represent strain life, Normal-strain life and Brown-Miller with Morrow mean correction factor models used to compute fatigue analysis [15], [32]

$$
\begin{aligned}
& \Delta \varepsilon=\frac{\sigma_{a}}{\mathrm{E}}+2\left(\frac{\sigma_{a}}{2 k^{\prime}}\right)^{\frac{1}{n^{\prime}}} \\
& \frac{\Delta \varepsilon}{2}=\frac{\sigma_{f}^{\prime}}{\mathrm{E}}(2 N)^{b}+\varepsilon_{f}^{\prime}(2 N)^{c} \\
& \frac{\Delta \varepsilon}{2}=1.65 \frac{\sigma_{f}^{\prime}-\sigma_{n \cdot m}}{\mathrm{E}}(2 N)^{b}+1.75 \varepsilon_{f}^{\prime}(2 N)^{c}
\end{aligned}
$$

where $\sigma_{n . m}$ is the mean normal stress on the critical plane, $2 N_{f}$ is the number of reversals to crack initiation, $\Delta \varepsilon_{N}$ is the normal strain on the critical plane, $\sigma_{f}^{\prime}$ is fatigue 
strength coefficient, $\mathcal{E}_{f}^{\prime}$ is normal fatigue ductility coefficient, E is the elastic modulus, $c$ is the fatigue ductility exponent, and $b$ is the fatigue strength exponent. Low cycle fatigue (LCF) test according to ISO 12106 and ASTM E606 is a fatigue test in which a cyclic load is simulated until failure. A commonly used equation that describes the behavior of low-cycle fatigue is the Coffin-Manson relation. The fatigue ductility exponent and coefficient are derived from the Coffin-Manson law:

$$
\varepsilon_{p}=\varepsilon_{f}^{\prime}(2 N)^{c}
$$

where $\varepsilon_{p}$ is the plastic strain. The fatigue strength exponent and coefficient are taken from Basquin's law:

$$
\varepsilon_{e}=\frac{\sigma_{a}}{E}=\frac{\sigma_{f}^{\prime}}{E}\left(2 N_{f}\right)^{b}
$$

where $\varepsilon_{e}$ is the elastic component of the cyclic strain amplitude, and $\sigma_{a}$ is the cyclic stress amplitude. The material properties are approximated using Seeger's method with the help of the re-scaling conventional monotonic ultimate tensile stress [15].

$$
\varepsilon_{t}=\varepsilon_{e}+\varepsilon_{p}
$$

Several methods have been developed to determine the mean stress. Mean stress, defined as the mean value of peak tensile stress and compressive one, has shown a significant effect on both deformation and fatigue behaviour[17]. Typically, Morrow's concept is suitable for low stress cycle fatigue and can be represented by the below equation:

$$
\frac{\sigma_{a}}{\sigma_{a v}}+\frac{\sigma_{n . m}}{\sigma_{f}^{\prime}}=1
$$

where $\sigma_{a}$ is the cyclic stress amplitude, $\sigma_{n . m}$ is the mean normal stress, $\sigma_{f}^{\prime}$ is the fatigue strength coefficient.

Table 2: Material parameters of Titanium alloy [15], [19], [26] 


\subsection{Experi-}

\section{mental setup}

\begin{tabular}{|l|l|}
\hline \multicolumn{2}{|c|}{ Material Parameters } \\
\hline$\sigma_{y}=$ Yield stress & $940 \mathrm{MPa}$ \\
\hline$\sigma_{U}=$ Ultimate strength & $1077 \mathrm{MPa}$ \\
\hline$\sigma_{f}^{\prime}=$ Stress coefficient & $1554.71 \mathrm{MPa}$ \\
\hline $\mathrm{b}=$ Stress exponent & -0.095 \\
\hline$\varepsilon_{f}^{\prime}=$ Strain coefficient & 0.35 \\
\hline $\mathrm{c}=$ Strain exponent & -0.69 \\
\hline $\mathrm{E}=$ Modulus of elasticity & $114000 \mathrm{MPa}$ \\
\hline$\varepsilon=$ Young's modulus & 0.34 \\
\hline$\rho=$ Density & $4.4 \mathrm{E}-09$ \\
\hline$k^{\prime}=$ Cyclic strain hardening coefficient & $1733.97 \mathrm{MPa}$ \\
\hline$n^{\prime}=$ Cyclic strain hardening exponent & 0.11 \\
\hline$S_{f}=$ True fracture strength & $1798.59 \mathrm{MPa}$ \\
\hline
\end{tabular}

In this research, the EOS M290 3D printer - a direct metal laser sintering (DMLS) additive manufacturing system (specifications listed in Table 3) - is used for sample preparation on a Titanium Ti64ELI powder.

Table 3: Direct Metal Laser Sintering machine (EOS M290) specifications.

\begin{tabular}{lc}
\hline Parameter & Values \\
\hline Laser power & Yb fibre laser: $400 \mathrm{~W}$ \\
Scan speed & Up to $7.0 \mathrm{~m} / \mathrm{s}$ \\
Wavelength & $1060-1100$ \\
Build area & $250 \times 250 \times 325$ \\
Diameter of laser beam & $100-500 \mu \mathrm{m}$ \\
\hline
\end{tabular}

The physical specimens were tested ( $\mathrm{n}=3,10 \mathrm{~Hz}, \mathrm{R}=0.1$ ) using an MTS Acumen fatigue machine until fracture occurred (see Figure 4). The specimens were fixed according to the International Standard of dynamic testing of single-post endosseous dental implants, which were replicated in the FEA model [33]. It was reported that under ISO protocol testing in air and normal saline solution are equivalent in terms of likelihood of fracture versus runouts [34]. As such, the current study consider air as testing environment. The experimental models were tested at $80 \%$ of the maximum load, as recommended by ISO 14801, and this maximum load was derived from FEA model [15], [33]. Dental implants with a diameter of $3.4 \mathrm{~mm}$ were 3D printed and the crown and onepiece dental implant were printed as one unit, as illustrated in Figure 6.

Figure 4: [A] Full view of MTS Acumen fatigue testing machine, [B] Detailed setup of 3D printed dental implant, specimen holder inclined at $30^{\circ}$ and load cell in vertical direction (axial loading). 


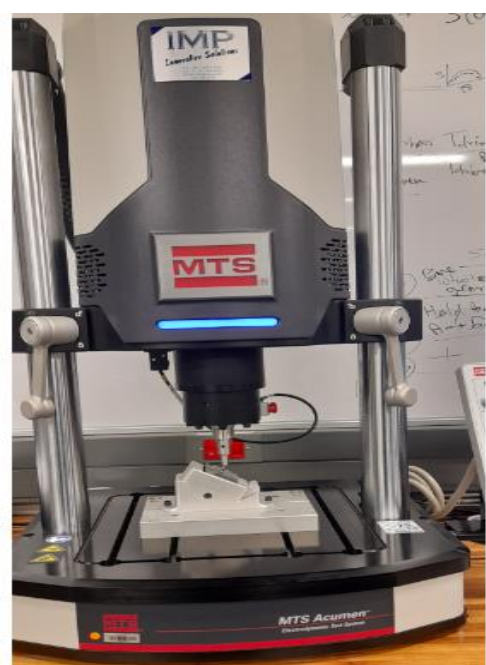

[A]

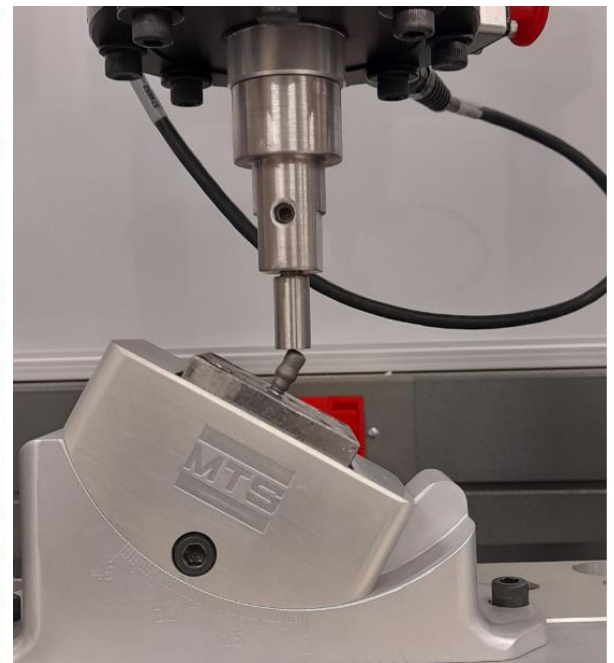

[B]

Figure 5: [A] Showing 3D-printed Dental implants before heat-treatment, [B] Showing 3D-printed Dental implants after heat-treatment. The heat treatment were performed for 2 hours hold at $800{ }^{\circ} \mathrm{C}$ in protective Argon atmosphere.

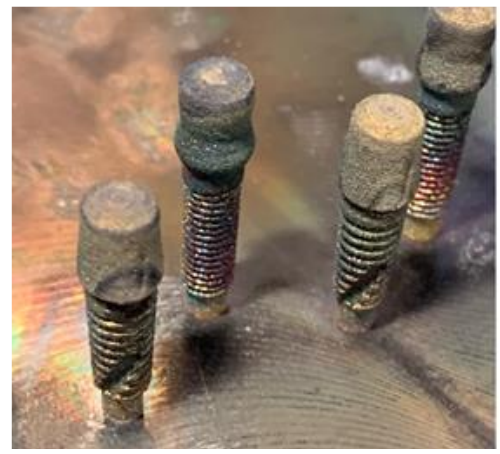

[A]

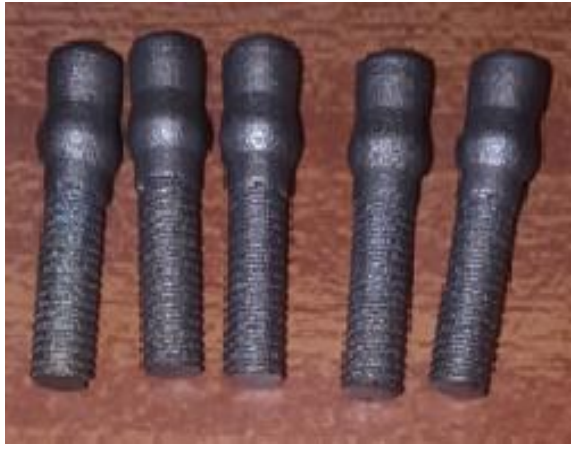

[B]

\section{Results}

The 3D model was simulated successfully and had good similarity with the physical specimens. The performance is predicted at $80 \%$ of the maximum loading $(810.5 \mathrm{~N})$ and the clinical success of the specimens was evaluated by computing the number of years that the dental implants will likely survive. The contour plot results are presented in two parts, the maximum loading and $80 \%$ of the maximum load, as shown in the Figure 6 .

\subsection{Finite element analysis (FEA) Results}

Figure 6: Contour plot [A] Maximum deflection in (mm), [B] Maximum von-Mises stress $(\mathrm{MPa})$ applied at static loading, results at maximum loading. 


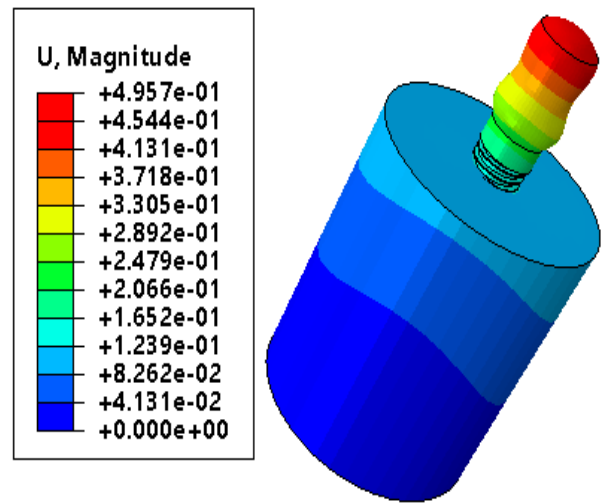

[A]
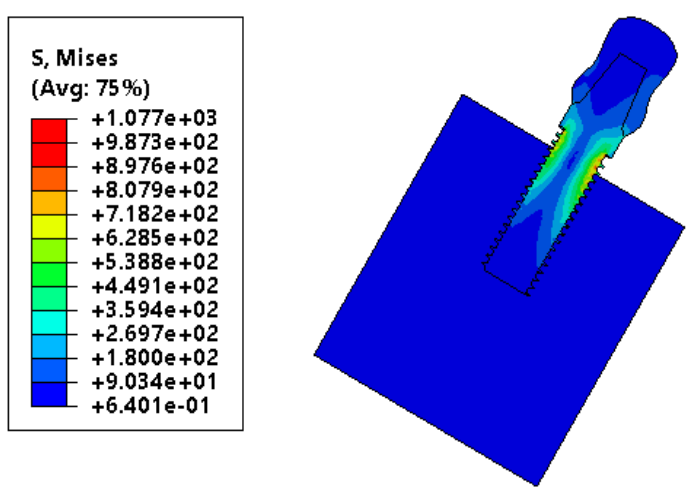

[B]

Figure 7: Maximum Von-mises (MPa), results at $80 \%$ to the maximum loading.

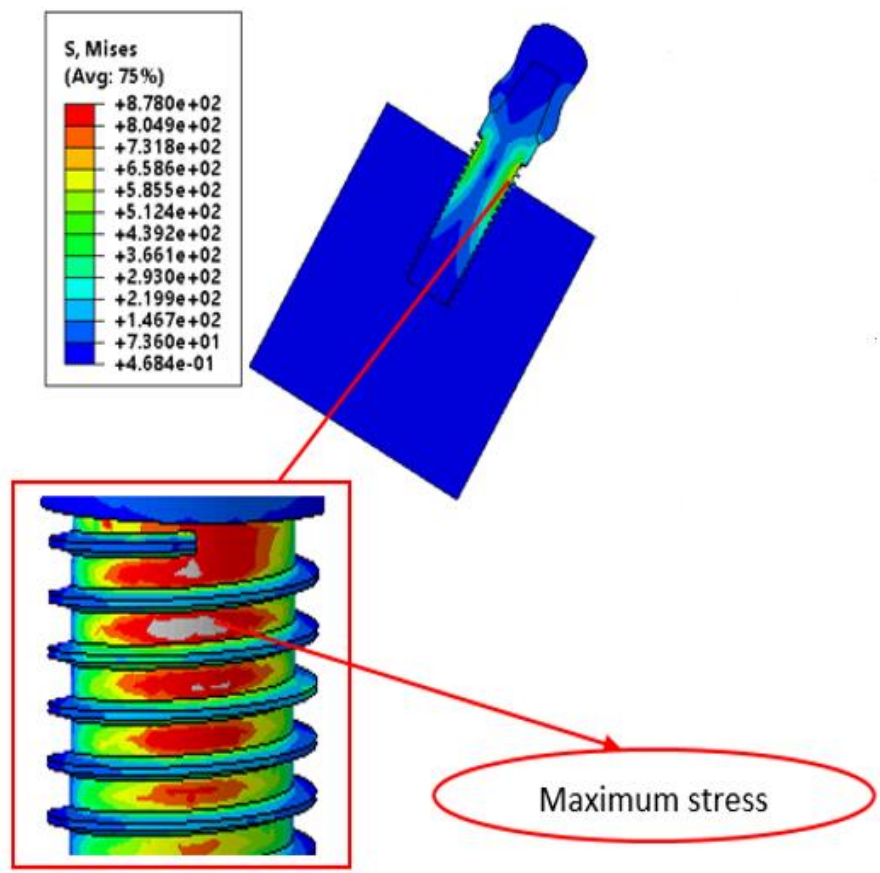

Figure 8: $[\mathrm{A}-\mathrm{B}]$ Fatigue analysis results for Normal strain algorithm.

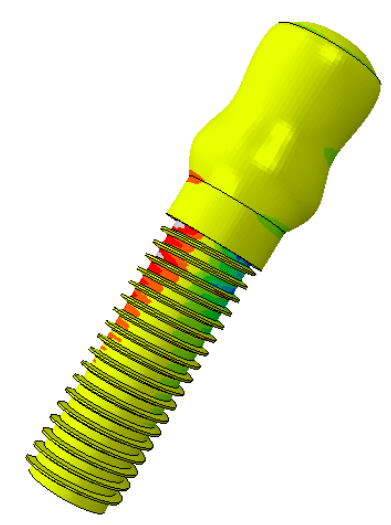

[A]
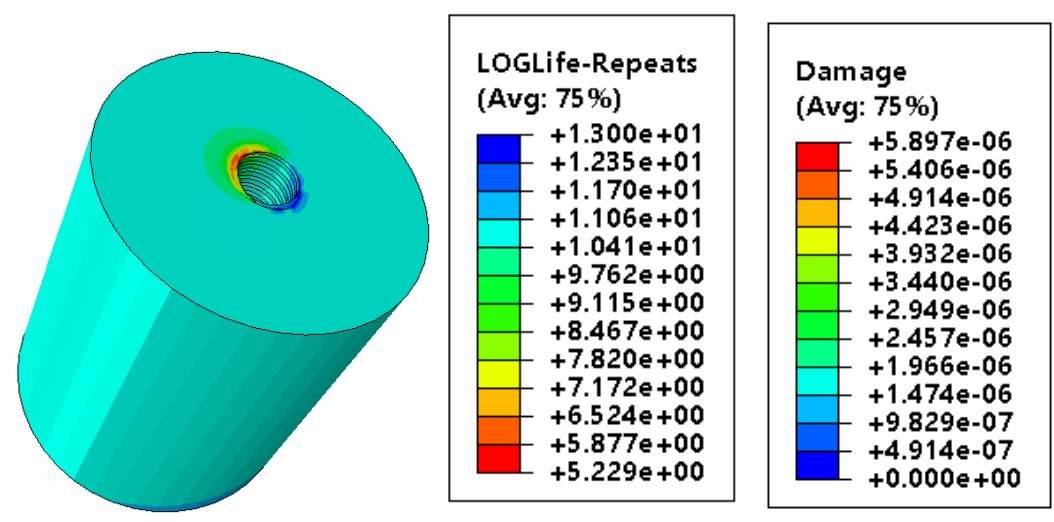

[B]

Figure 9: [A-B] Fatigue analysis for Brown-Miller with Morrow mean correction factor 


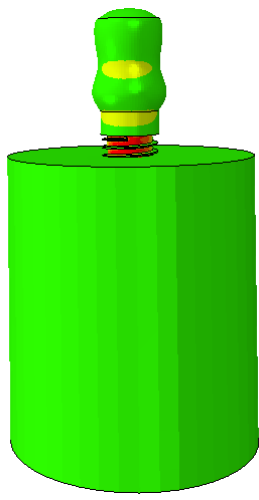

[A]
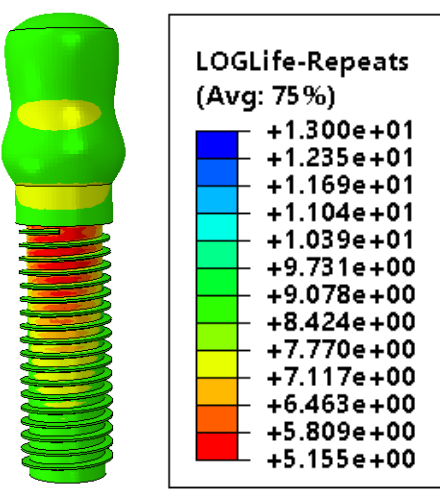

[B]

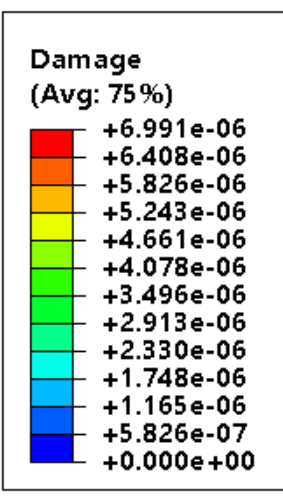

$+0.000 e+00$

The ISO14801 recommends that minimum of two threads be exposed when testing the implants, see Figure 6(B). The contour plot in Figure 7 shows the higher stresses that are located in the contact area between implant and specimen holder. The $80 \%$ load show the maximum stress of $876 \mathrm{MPa}$. Loglife results shows that the dental implant will survive 19.36 years under Normal strain and 16.33 years under Brown-Miller with Morrow mean correction factor, as seen in Table 4. The maximum damage was observed under BrownMiller with Morrow mean correction factor, with a figure of $6.991 \times 10^{-6}$. Surface roughness between the dental implant and the mandibular bone plays a critical role in determining a life of the implant and initial stability [35]. The surface roughness of $1.6<\mathrm{Ra}<4 \mathrm{~mm}$ was selected based on previous studies [36], [37].

Table 4: Fatigue analysis results with the loading set to $80 \%$ of the maximum loading. Loglife, Cycles, useful life (clinical success) and damage to the 3D printed dental implant are presented.

\begin{tabular}{lcccccc}
\hline Algorithm & Load $(\%)$ & $\begin{array}{c}\text { Surface } \\
\text { finish }\end{array}$ & Loglife & Cycles & $\begin{array}{c}\text { Useful Life } \\
{[\text { Years }]}\end{array}$ & $\begin{array}{c}\text { Damage } \\
{\left[\times 10^{-6}\right]}\end{array}$ \\
\hline Normal strain & $80 \%$ & $1,6<\mathrm{Ra}<4 \mathrm{~mm}$ & 5.23 & 169565.5 & 19.36 & 5.89 \\
$\begin{array}{l}\text { Brown Miller: } \\
\text { Marrow mean }\end{array}$ & $80 \%$ & $1,6<\mathrm{Ra}<4 \mathrm{~mm}$ & 5.16 & 143040.7 & 16.33 & 6.99 \\
\hline
\end{tabular}

\subsection{Experimental results}

The experimental model was developed to validate FEA fatigue results. The maximum load from a static loading of $648.4 \mathrm{~N}$ was used. A sinusoidal wave was used to apply the cyclic load, where the loading ratio was set at $10 \%$. According to the Goodman Criterion, the expected life for the abutment screw would be 111640 cycles and this is considered against a human performing 325 acts of mastication per day [38].

Table 5: Fatigue experimental study results representing the clinical success of each 3D printed dental implant.

Samples Cycles Useful




\begin{tabular}{ccc} 
& & Life [Years] \\
\hline 1 & 262142 & 29.92 \\
2 & 137433 & 15.67 \\
3 & 169624 & 19.36 \\
4 & 169566 & 19.35 \\
5 & 143041 & 16.33 \\
6 & 258874 & 29.55 \\
7 & 140657 & 16.06 \\
8 & 207305 & 23.66 \\
9 & 158304 & 18.07 \\
10 & 150370 & 17.17 \\
\hline Average & & 20.51 \\
\hline
\end{tabular}

The failure of the 3D printed dental implant occurred in the second and third threads, which is in agreement with FEA results (see Figure 10). The cycle target was set for $5 \times 10^{6}$ cycles but, with a loading of $80 \%$, it was observed that a minimum of 137433 and maximum of 262142 cycles respectively could be reached before failure occurs. The clinical success of the 3D printed dental implants is 20.51 years respectively when masticatory loading of $648.4 \mathrm{~N}$ is applied.

Figure 10: Fractured 3D-printed dental implants after experimental study according to ISO 14801 standard's fatigue test.

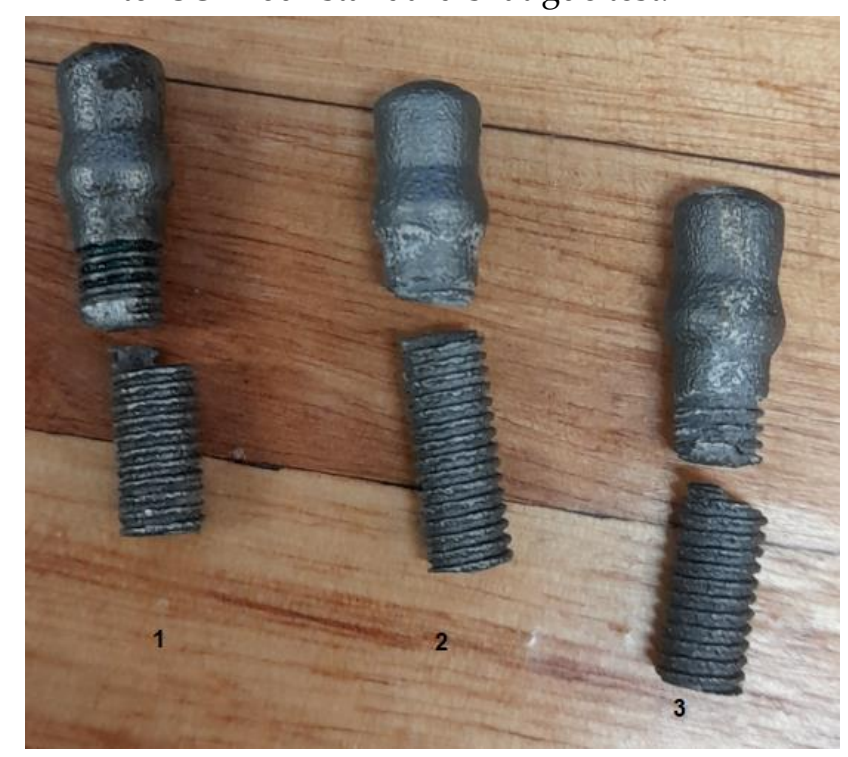

\subsection{Statistical modelling of 3D-printed dental implant}

The model validation is a useful tool in further quantifying that the FEA fatigue results are correct. The experimental models were 3D-printed and fatigue testing was performed in dry air conditions. The experimental results were reported in Table 6, ten 
(10) samples were test and the results are compared with Normal strain and Brown-Miller with Morrow mean correction factor. The percentage error of each model is calculated. Table 7 and 8 shows the ANOVA and coefficient estimates of the model. This coefficient is the mean adjustment and represents the expected change in response per unit change in the value of the factor if the other factors remain constant. ANOVA analysis is a regression analysis used to investigate the effects of response output factors that find factors that are noted to affect the process, based on the priority confidence intervals in the model [39].

Table 6: Comparison of 3D printed dental implants clinical success between Computational 3D model and experimental model.

\begin{tabular}{cccc}
\hline & Experimental data & $\begin{array}{c}\text { Normal strain [FEA] } \\
169565.5[\mathbf{1 9 . 3 5} \\
\text { years] }\end{array}$ & $\begin{array}{c}\text { Brown miller [FEA] } \\
\text { Cycles }\end{array}$ \\
\hline YYears] & Experimental data & 54.63 & $\%$ \\
\hline 262142 & 29.92 & 19.02 & 83.33 \\
137433 & 15.67 & 0.05 & 3.98 \\
169624 & 19.36 & 0 & 18.67 \\
169566 & 19.35 & 15.67 & 18.57 \\
143041 & 16.33 & 52.17 & 0.06 \\
258874 & 29.55 & 17 & 81.07 \\
140657 & 16.06 & 22.27 & 1.59 \\
207305 & 23.66 & 6.87 & 44.97 \\
158304 & 18.07 & 11.23 & 10.72 \\
150370 & 17.17 & 19.89 & 5.21 \\
\hline Average & 20.51 & & 26.82 \\
\hline
\end{tabular}

Computational statistical estimators, F-numbers, and $\mathrm{R}^{2}$ values were used to determine that the model was statistically valid. F-value is a test that compares the root mean square to the residual mean square, checking if the model is significant or not.

\begin{tabular}{lcccccc}
\hline Source of Variation & $S S$ & $d f$ & $M S$ & $F$ & P-value & F crit \\
\hline Normal strain & 8924.08 & 9 & 991.56 & 4.6326 & 0.0027 & 2.4562 \\
Brown-miller & 293.62 & 2 & 146.81 & 0.6859 & 0.5163 & 3.5545 \\
Error & 3852.66 & 18 & 214.04 & & &
\end{tabular}


Total $13070.36 \quad 29$

Table 7: ANOVA for FEA and experiment model response on 3D-printed dental implants.

Table 8: Correlation coefficients estimates

\begin{tabular}{lc}
\hline Correlations & Coefficient $\left(\mathrm{R}^{2}\right)$ \\
\hline Experimental vs Normal strain & 0.8256 \\
Experimental vs Brown-miller & 0.9973 \\
Normal vs Brown-miller & 0.8484 \\
\hline
\end{tabular}

\section{Discussion}

The results of this research are presented and the study relies on the production method of the dental implants, which is 3D printing. The dental implants were 3D-printed and computational models were developed to analyse stress distribution and predict the life of the 3D-printed dental implant. The results presented herein are not limited to the implants themselves but apply more generally to the material they are made of, namely Ti64V ELI and the production method.

Two vital parameters that lead to success with dental implants are design and insertion technique [40]. The design of dental implant plays an important role in the stress distribution that occurs primarily where bone is in contact with dental implant [41]. The clinical reports showed dental implant body fracture was more frequently observed in reduced-diameter implants as compared to regular-diameter implants [31]. The choice of pitch size was conceded because, the finer the pitch, the more threads on the dental implant body and the more complex the 3D-printing process will be. In the present study, the pitch size lies between $0.6-0.8 \mathrm{~mm}$ and the dental implant is $3.4 \mathrm{~mm}$ in diameter.

The combination of experimental and finite element analysis models for stress analysis is capable of providing reliable results [41]-[43]. However, FEA studies of dental implants with validation experiments are relatively rare [44]. The maximum stress levels of the implant-bone boundary influence biological reactions, including bone resorption and remodelling [45], [46]. Orthodontics is gradually changing from opinion-based practice to evidence-based practice [47]. In the present study, a specimen holder was used to fix the 3D-printed dental implant during the experimental test and FEA analysis. The same methodology was previously applied successfully [15], [21], [48].

Oblique loads generate higher stress and displacement that is much greater than that produced by axial loading [23], [49], [50]. In the current study, we simulated a masticatory 
scenario in an oblique loading and in which a $648.4 \mathrm{~N}$ force was applied on the top surface of the crown, obliquely and at $30^{\circ}$ to the longitudinal axis of the 3D printed dental implant (see Figure 3). In our results, $30^{\circ}$ of loading direction showed the highest stress concentration between the second and third threads and this was due to worst-case scenario masticatory simulation. This is in agreement with previous work [20], [51]. Generally, Titanium materials have a low elastic modulus, which can eliminate bone resorption problems and minimise height contact stress between the bone and dental implant [52], [53].

The clinical evaluation of dental implant stress distribution is important because it is possible to predict where the fracture or failure will occur [11], [23], [27], [54]. Fatigue may cause such implants to break, with serious consequences from a clinical standpoint [55]. The fatigue algorithms used in the current study are Normal strain and Brown-Miller with Morrow mean correction factor [17]. The results show that Normal strain led to 169565.5 cycles and that Brown-Miller with Morrow mean correction factor led to 143040.7 cycles (Table 4). These figures were then divided by the number of masticatory cycles per year and clinical success was estimated. The clinical success of the Normal strain is 19.36 years and Brown-Miller with Morrow mean correction factor is 16.33 years see Table 4 .

The FEA results were then used to calculate percentage error against experimental results seen Table 6. The life prediction model exhibit an average life of 19.89 in Normal strain, 26.82 Brown -miller and 20.51 experimental. By comparing fatigue results (experimental and finite element analysis), it was revealed that Brown-Miller with Morrow mean correction factor exhibits the highest useful life, as compared to Normal strain. In addition, it was predicted by FEA analysis that stress concentration was at the root of the implant body screw thread adjacent to the simulated bone level (Figure 7). This result correlates well with the consistent failure mode of implant body fracture among all of the tested implants (Figure 10).

The brittle nature of titanium (Ti64V ELI) tested in air media was observed in all samples and exhibited the shear stress failure (see Figure 10). Similar to the findings of other studies, oblique forces were used to develop FEA models and the results were then exported to the Fe-Safe software for fatigue analysis [11], [18], [38]. The phenomenon of fatigue in orthodontics is of vital importance and, as the global number of individuals receiving dental implants increases, bone loss, fractured dental implants and peri-implant diseases are growing problems in clinical dentistry [53], [56].

The models were then validated experimentally by performing fatigue experimental tests and ANOVA was used to analysis the results. If the ratio of the F-value is close to one, it is unlikely any factor has a significant effect on the Normal strain. However, in Table 7, the model F-value of 4.6326, which means the model for the Normal strain response to the experimental results. Once the p-value is less than 0.05 , the terms of the model have a significant effect on the response output. The Model's p-value for the Normal strain, which is 0.0027 , implies that the model terms are also significant. Similarly, the Brown-miller has an F-value of 0.6859 and a p-value of 0.5163 , implying that the model is insignificant. The $\mathrm{R}^{2}$ values greater than 0.5 are generally considered to be a moderate to strong size effect, which is desirable. Calculating the correlation coefficient between the experiment and the finite element analysis model, it was found that $\mathrm{R}^{2}$ of the experiment 
vs. Normal strain was 0.8256 , experiment vs. Brown-miller was 0.9973 , and Normal vs. Brown-miller was 0.8484 . Thus, this confirms that there are no issues with the data or the model. This study can provide a starting point for analysis of 3D-printed dental implants and the possibility of using these in design of dental implant. The importance of the results is stressed, given the small size of 3D-printed dental implants, which can present problems of scale when they are manufactured by the additive manufacturing technique.

\section{Limitations of this study}

Small sample number $(n=10)$ reduces the predictive ability of the study from a statistical point of view. Future studies will seek to overcome this shortcoming by using a larger sample number. The test is limited to dry air condition testing environment. Single angle is considered for worst case scenario. The study considered single body dental implant, this is a limitation of the methodology due to the difficulties in 3D-printing of dental implants.

\section{Conclusion}

The possibility of using finite element analysis in predicting the performance of 3D printed dental implants was investigated. The life prediction differences between two algorithms were reported and it was found that the 3D-printed dental implants in the current study exhibit their highest performance under the Normal strain method, as opposed to the Brown-Miller with Morrow mean correction factor. The highest stress is observed between the second and third threads in the FEA model. The experimental implants failed between the third and fourth threads. Lastly, it was observed that there is a strong correlation between the projected FEA results and the results achieved during experimental testing. The results shows that the Normal strain is 19.89 years, BrownMiller with Morrow mean correction factor is 26.82 years, and experimental is 20.51 years. The ANOVA analysis of variance shows the relationship between FEA and the experiment, and the results show that the p-value of the normal strain is less than 0.05 , which means that the model term is significant. Therefore, the correlation coefficient is less than 1, indicating that there is no problem between FEA and experimental data. Through comparison, it can be seen that the model prediction and the actual experimental data obey the normal distribution.

\section{Declarations}

\section{- Acknowledgments}

The research is supported by the Tshwane University of Technology and the University of South Africa (UNISA). The experiments were performed in biomechanics laboratory facilities at University of South Africa's Science campus in Johannesburg, South Africa.

\section{- Availability of data and materials}

The datasets used and/or analysed during the current study are available from the corresponding author on reasonable request. 


\section{- Competing interests}

The author declares that he has no conflict of interest.

\section{- $\quad$ Funding}

The project was funded through the Tshwane University of Technology scholarship and University of South Africa (UNISA) research funding.

\section{- $\quad$ Authors' contributions}

LC developed the project, conceptualise the work, conduct experiments and analysis, and write the paper. DA read and approved the final manuscript. HM read and approved the final manuscript. F read and approved the final manuscript.

\section{References}

1. S. Isabel and C. Ribeiro, "Dental Implants Resistance : Computational Analysis," no. November, 2016.

2. A. Agnieszka and O. N. Y. Adam, "Stress analysis of dental implant inserted in the mandible," vol. 68, no. 1, pp. 25-32, 2018.

3. S. Cinel, E. Celik, E. Sagirkaya, and O. Sahin, "Experimental evaluation of stress distribution with narrow diameter implants: A finite element analysis," J. Prosthet. Dent., vol. 119, no. 3, pp. 417-425, 2018.

4. A. Chakraborty, P. Datta, S. Majumder, S. C. Mondal, and A. Roychowdhury, “CT of Mandible," Comput. Biol. Med., p. 103839, 2020.

5. B. Ren et al., "Improved osseointegration of 3D printed Ti-6Al-4V implant with a hierarchical micro/nano surface topography: An in vitro and in vivo study," Mater. Sci. Eng. C, vol. 118, no. September 2020, p. 111505, 2021.

6. Y. Xiong et al., "Fatigue behavior and osseointegration of porous Ti-6Al-4V scaffolds with dense core for dental application," Mater. Des., vol. 195, p. 108994, 2020.

7. F. Edith, J. Yong, M. Shyan, P. Nian, F. Goh, and C. Wen, "Printing of Titanium implant prototype," Mater. Des., vol. 31, pp. S101-S105, 2010.

8. R. Jiang, R. Kleer, and F. T. Piller, "Predicting the future of additive manufacturing: A Delphi study on economic and societal implications of 3D printing for 2030," Technol. Forecast. Soc. Change, vol. 117, pp. 84-97, 2017.

9. U. B. Sheela, P. G. Usha, M. M. Joseph, J. S. Melo, S. T. Thankappan Nair, and A. Tripathi, 3D printing in dental implants. Elsevier (Singapore) Pte Ltd, 2021.

10. M. M. Ahsan, “3D Printing and Titanium Alloys : A Paper Review," Eur. Acad. Res., vol. III, no. 10, pp. 1114411154, 2016.

11. M. A. Pérez, "Life prediction of different commercial dental implants as influence by uncertainties in their fatigue material properties and loading conditions," Comput. Methods Programs Biomed., vol. 108, no. 3, pp. 1277-1286, 2012.

12. R. B. Osman and M. V. Swain, "A Critical Review of Dental Implant Materials with an Emphasis on Titanium versus Zirconia," Materials (Basel)., vol. 8, no. March, pp. 932-958, 2015.

13. M. Prados-privado et al., "Long-Term Fatigue and Its Probability of Failure Applied to Dental Implants," vol. 2016, 2016.

14. A. Y. J. Wu, J. T. Hsu, W. Chee, Y. Te Lin, L. J. Fuh, and H. L. Huang, “Biomechanical evaluation of one-piece and two-piece small-diameter dental implants: In-vitro experimental and three-dimensional finite element 
analyses," J. Formos. Med. Assoc., vol. 115, no. 9, pp. 794-800, 2016.

15. W. W. Nagy and J. A. Griggs, "Fatigue lifetime prediction of a reduced-diameter dental implant system : Numerical and experimental study," Dent. Mater., pp. 1-11, 2018.

16. D. Bordin, E. T. P. Bergamo, P. Fardin, P. G. Coelho, and E. A. Bonfante, "Author' s Accepted Manuscript," J. Mech. Behav. Biomed. Mater., 2017.

17. S.-P. Zhu, Q. Lei, H.-Z. Huang, Y.-J. Yang, and W. Peng, “Mean stress effect correction in strain energy- based fatigue life prediction of metals," Int. J. Damage Mech. 26(8), no. October 2017, 2017.

18. U. R. Patil, P. . Dhatrak, and B. . Shinde, "Fatigue Life of Dental Implant- A Review," IOSR J. Mech. Civ. Eng., vol. 04, no. 04, pp. 01-05, 2016.

19. Y. T. Tsai and K. S. Wang, "A study of reliability analysis of fatigue life for dental implants," J. Chinese Soc. Mech. Eng. Trans. Chinese Inst. Eng. Ser. C/Chung-Kuo Chi Hsueh K. Ch'eng Hsuebo Pao, vol. 36, no. 5, pp. 439448, 2015.

20. S. Aumnakmanee, N. Yodpiji, and N. Jantong, "Finite element analysis of dental implant prosthetics Suchat," Mater. Today Proc., vol. 5, no. 3, pp. 9525-9534, 2018.

21. K. Shemtov-Yona, M. Özcan, and D. Rittel, "Fractographic characterization of fatigued zirconia dental implants tested in room air and saline solution," Eng. Fail. Anal., vol. 96, no. October, pp. 298-310, 2019.

22. H. A. Shirazi, M. Ayatollahi, A. Karimi, and M. Navidbakhsh, "A comparative finite element analysis of two types of axial and radial functionally graded dental implants with titanium one around implant-bone interface," Sci. Eng. Compos. Mater., vol. 24, no. 5, pp. 747-754, 2017.

23. C. Tang et al., "Nonlinear finite element analysis of three implant - abutment interface designs," no. February, pp. 101-108, 2012.

24. S. Najeeb et al., 21. Dental implants materials and surface treatments. Elsevier Ltd, 2019.

25. R. Amid, S. Raoofi, M. Kadkhodazadeh, M. R. Movahhedi, and M. Khademi, "Effect of microthread design of dental implants on stress and strain patterns: A three-dimensional finite element analysis," Biomed. Tech., vol. 58, no. 5, pp. 457-467, 2013.

26. G. De la Rosa, R. Castolo, V. G. Perez, and P. Arnoux, "Mechanical strength and fracture point of a dental implant under certi fi cation conditions : A numerical approach by fi nite element analysis," J. Prosthet. Dent., pp. $1-9,2017$.

27. H. S. Asgharzadeh, M. R. Ayatollahi, and A. Asnafi, "To reduce the maximum stress and the stress shielding effect around a dental implant-bone interface using radial functionally graded biomaterials," Comput. Methods Biomech. Biomed. Engin., vol. 20, no. 7, pp. 750-759, 2017.

28. P. Dhatrak, U. Shirsat, S. Sumanth, and V. Deshmukh, "ScienceDirect Finite Element Analysis and Experimental Investigations on Stress Distribution of Dental Implants around Implant-Bone Interface," Mater. Today Proc., vol. 5, no. 2, pp. 5641-5648, 2018.

29. M. R. Niroomand and M. Arabbeiki, "Implant stability in different implantation stages: Analysis of various interface conditions," Informatics Med. Unlocked, vol. 19, no. March, p. 100317, 2020.

30. M. Prados-Privado, J. A. Bea, R. Rojo, S. A. Gehrke, J. L. Calvo-Guirado, and J. C. Prados-Frutos, “A New Model to Study Fatigue in Dental Implants Based on Probabilistic Finite Elements and Cumulative Damage Model," Appl. Bionics Biomech., vol. 2017, 2017.

31. K. Shemtov-Yona and D. Rittel, "Fatigue failure of dental implants in simulated intraoral media," J. Mech. Behav. Biomed. Mater., vol. 62, pp. 636-644, 2016.

32. Dassault System Simulia, "Fe-Safe 2017 - Fe-Safe User Guide," 2017.

33. BSI Standards Publication dentistry, "BSI Standards Publication Dentistry - Implants - Dynamic loading test for endosseous dental implants," 2016. 
34. A. T. Miller, "Fatigue and Cyclic Loading of 3D Printed Soft Polymers for Orthopedic Applications," no. May, p. 187, 2017.

35. O. Obiukwu, N. Martin, B. Okafor, G. Lawa, and L. G. O.Obiukwu, M.Nwafor, B.Okafor, "The effect of surface finish on the low cycle fatigue of low and medium carbon steel'," Int. Conf. Mech Ind. Engg, no. August, 2015, [Online]. Available: https://www.researchgate.net/publication/335240807_The_Effect_of_Surface_Finish_on_the_Low_Cycle_Fatigue_of_Low_and_Medium_Carbon_Steel.

36. V. K. Wooding and R. F. Laubscher, "Variable length scale surface finish assessment of machined grade 4 titanium alloy," Procedia CIRP, vol. 13, pp. 90-96, 2014.

37. L. Tonietto, L. Gonzaga, M. R. Veronez, C. de S. Kazmierczak, D. C. M. Arnold, and C. A. da Costa, "New Method for Evaluating Surface Roughness Parameters Acquired by Laser Scanning," Sci. Rep., vol. 9, no. 1, pp. 1-16, 2019.

38. B. A. Hernandez and C. Foschini, "Fatigue Analysis of Dental Prostheses by Finite Element Method ( FEM ) IMECE2015-51911," no. January 2015, 2015.

39. S. K. Jalali, R. Yarmohammadi, and F. Maghsoudi, “Finite element stress analysis of functionally graded dental implant of a premolar tooth," J. Mech. Sci. Technol., vol. 30, no. 11, pp. 4919-4923, 2016.

40. J. B. Brunski and J. E. Lemons, Biomedical-Engineering Analyses of Mini Dental Implants. Elsevier, 2013.

41. J. Ferreira et al., "Finite element analysis on in $\mathrm{fl}$ uence of implant surface treatments, connection and bone types «," Mater. Sci. Eng. C, vol. 63, pp. 292-300, 2016.

42. V. Demenko, I. Linetskiy, L. Linetska, and O. Yefremov, "Load-carrying capacity of short implants in edentulous posterior maxilla : A finite element study," Med. Eng. Phys., 2019.

43. C. Vasak, G. D. Strbac, C. D. Huber, S. Lettner, A. Gahleitner, and W. Zechner, "Evaluation of three different validation procedures regarding the accuracy of template-guided implant placement: An in vitro study," Clin. Implant Dent. Relat. Res., vol. 17, no. 1, pp. 142-149, 2015.

44. Y. Chang, A. A. Tambe, Y. Maeda, M. Wada, and T. Gonda, “Finite element analysis of dental implants with validation : to what extent can we expect the model to predict biological phenomena? A literature review and proposal for classification of a validation process," 2018.

45. M. Omori, Y. Sato, N. Kitagawa, Y. Shimura, and M. Ito, "A biomechanical investigation of mandibular molar implants: reproducibility and validity of a finite element analysis model," Int. J. Implant Dent., vol. 1, no. 1, pp. 1-13, 2015, [Online]. Available: ???

46. L. Kong et al., "Selection of the implant thread pitch for optimal biomechanical properties: A three-dimensional finite element analysis," Adv. Eng. Softw., vol. 40, no. 7, pp. 474-478, 2009.

47. A. Sarmah, A. K. Mathur, V. Gupta, V. S. Pai, and S. Nandini, "Finite Element Analysis of Dental Implant as Orthodontic Anchorage," vol. 12, no. August, pp. 259-264, 2011.

48. E. Homaei et al., "Fatigue resistance of monolithic CAD / CAM ceramic crowns on human premolars," Ceram. Int., vol. 42, no. 14, pp. 15709-15717, 2016.

49. M. M. Oswal, U. N. Amasi, M. S. Oswal, and A. S. Bhagat, "Influence of three different implant thread designs on stress distribution: A three-dimensional finite element analysis," J. Indian Prosthodont. Soc., vol. 16, no. 4, pp. 359-365, 2016.

50. V. Demenko, I. Linetsky, V. Nesvit, L. Linetska, and A. Shevchenko, "FE study of bone quality effect on loadcarrying ability of dental implants," Comput. Methods Biomech. Biomed. Engin., vol. 17, no. 16, pp. 1751-1761, 2014.

51. A. D. Schwitalla, M. Abou-emara, T. Spintig, J. Lackmann, and W. D. Müller, "Finite element analysis of the biomechanical effects of PEEK dental implants on the peri-implant bone," J. Biomech., vol. 48, no. 1, pp. 1-7, 2015. 
52. T. H. Lan, J. K. Du, C. Y. Pan, H. E. Lee, and W. H. Chung, “Biomechanical analysis of alveolar bone stress around implants with different thread designs and pitches in the mandibular molar area," Clin. Oral Investig., vol. 16, no. 2, pp. 363-369, 2012.

53. C. Chang Tu, P. I. Tsai, S. Y. Chen, M. Y. P. Kuo, J. S. Sun, and J. Z. C. Chang, “3D laser-printed porous Ti6Al4V dental implants for compromised bone support," J. Formos. Med. Assoc., vol. 119, no. 1P3, pp. 420429, 2020.

54. T. A. Soliman, R. A. Tamam, S. A. Yousief, and M. I. El-Anwar, "Assessment of stress distribution around implant fixture with three different crown materials," Tanta Dent. J., vol. 12, no. 4, pp. 249-258, 2015.

55. J. M. Ayllón, C. Navarro, J. Vázquez, and J. Domínguez, “Fatigue Life Estimation in Dental Implants," Eng. Fract. Mech., 2014.

56. Z. Wang and Y. Zhou, "Fatigue lifetime prediction of a 3D-printing dental implant by Finite Element Analysis," MATEC Web Conf., vol. 232, p. 02060, 2018.

57. M. Dada, P. Popoola, N. Mathe, S. Pityana, and S. Adeosun, "Parametric optimization of laser deposited high entropy alloys using response surface methodology ( RSM )," Int. J. Adv. Manuf. Technol., vol. 109, pp. 2719$2732,2020$. 